This item was submitted to Loughborough's Research Repository by the author.

Items in Figshare are protected by copyright, with all rights reserved, unless otherwise indicated.

\title{
How practitioners deal with their clients' "off-track" talk
}

\section{PLEASE CITE THE PUBLISHED VERSION}

http://dx.doi.org/10.1075/pbns.252.02ant

\section{PUBLISHER}

(c) John Benjamins

\section{VERSION}

AM (Accepted Manuscript)

\section{LICENCE}

CC BY-NC-ND 4.0

\section{REPOSITORY RECORD}

Antaki, Charles. 2019. "How Practitioners Deal with Their Clients' "off-track" Talk". figshare.

https://hdl.handle.net/2134/16554. 


\title{
Charles Antaki
}

\section{How practitioners deal with their clients' "off-track" talk}

\author{
Abstract \\ In institutional encounters where a client engages with a practitioner for advice \\ or guidance, there is a phase in which the client may be expected to 'tell their \\ tale' before the practitioner offers a response. In this chapter I shall analyse the \\ kind of professional conversation which involves with a client being invited to \\ describe a personal and indeed intimate problem, in order for the professional to \\ offer their perspective (and possibly suggest a solution). The client's problems \\ here are matters of emotion, conflict or life-style, caused or sharpened by \\ psychological disorder or disability - in other words, we shall be listening in to \\ what the editors term as the 'professional format' of the counselling, personal- \\ support and therapy consultation.
}

Keywords:

Explanations, accounts, therapy 
In institutional encounters where a client engages with a practitioner for advice or guidance, there is a phase in which the client may be expected to 'tell their tale' before the practitioner offers a response. That is the 'interaction type', as the editors of this volume usefully call it, that I shall concentrate on in this chapter. As the editors say, "interaction types ... are ... bounded (parts of) conversations with an inherent structuring of opening, core interaction and closing section, in which participants solve complex communicative tasks." (Graf, Sator and Spranz-Fogasy, this volume, p. xxx). What I have in my sights is that kind of professional conversation which involves with a client being invited to describe a personal problem, in order for the professional to offer their perspective (and possibly suggest a solution). The client's problems here are matters of emotion, conflict or life-style, caused or sharpened by psychological disorder or disability - in other words, we shall be listening in to what the editors term as the 'professional format' of the counselling, personalsupport and therapy consultation.

Common to all of these is the need for the practitioner to get their client to tell their troubles in some sort of narrative. The communicative task facing both parties is getting this narrative ' right' - tailoring its delivery (length, detail, content) to the needs of the conversation at that point. My interest is in what happens when that tailoring goes wrong, and the narrative is stopped or diverted 
by the practitioner, who has judged that the client has strayed too far from the agenda - that the client has gone "off-track". Dealing with such behaviour is a complex business, and, as we shall see, the practitioner needs to try and be firm while also being supportive.

How might a client go 'off-track'? In ritualised settings the troubles-telling stage of the proceedings is fixed and clear to both parties (for example, in a religious confessional, where the question-and answer format limits the penitent to a set time in which to recount her or his sins), and there are conventional or ritualised formats in which to deliver the trouble-description. But in more mundane interactions the boundaries are diffuse. This chapter is about what happens when the client's troubles tale is treated by the practitioner as having spilled over into an inappropriate part of the encounter - perhaps starting too soon, going on too long, or re-emerging after it had been apparently dealt with. I will be dealing with such policing of boundaries in two very different settings in the helping professions: sessions of psychotherapy, and interactions between support-staff and people with intellectual impairments. We shall see that the manner in which very different practitioners deal with the problem of 'off-track' talk (indeed, whether it is a problem) shares common conversational features, and becomes itself a constituent part of what the institutional service provides. 


\section{Ordinary practices for discouraging talk}

An institution's ways of talking is only a variant of what happens in the primordial site of interaction, which is everyday conversation (which must necessarily have predated the development of institutions). And, in everyday conversation, there is a range of practices by which a person might treat another's talk as being off-track, or otherwise not to be encouraged. Both parties will have an eye to what Schegloff calls the progressivity of a speaker's actions in the turn they're currently constructing (Schegloff, 1979) or in the sequence that they're building (Schegloff, 2007); and at any point one participant may decide to encourage the other in their trajectory or, conversely, steer them away from the line they are taking. Encouragement is the norm, and Example 1 shows an example of encouragement in the arrowed lines.

Extract 1 (Rahman 1 4-6, notation greatly simplified)

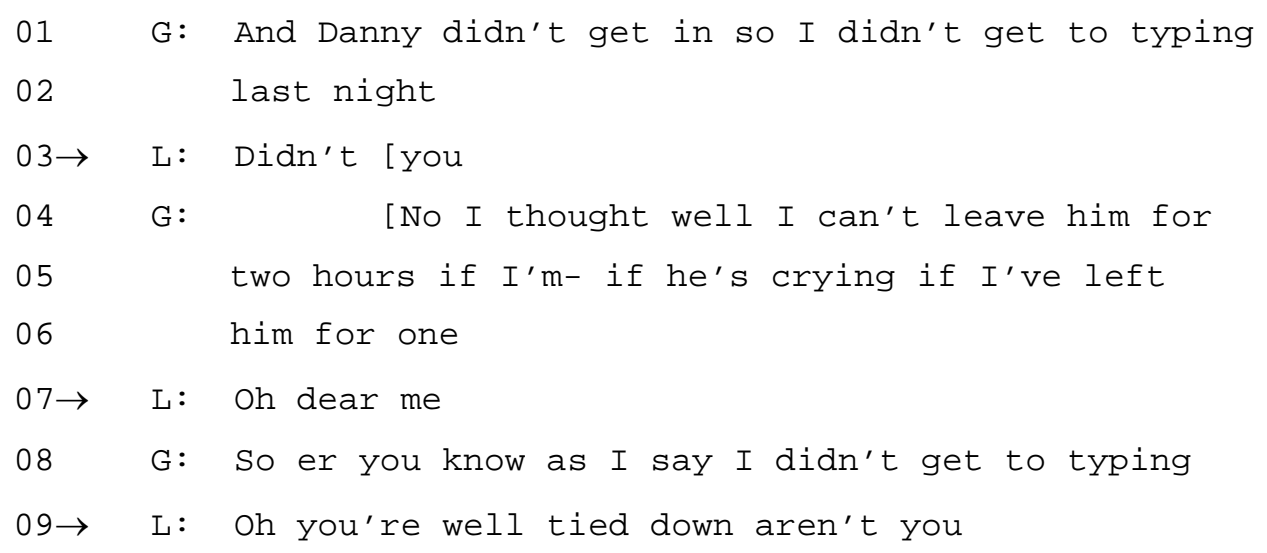


Speaker G is telling a tale about her son's crying preventing her from typing, and speaker L's contributions are all news receipts of an encouraging, go-ahead kind (see Heritage, 1984 for the range), fitted to the newsworthiness of what is being announced, its emotional tone and showing, at line 9, an appreciation of its truth and aptness. Were the recipient of news less inclined to encourage the news-teller, they might steer them away from it gently or brusquely, forming a gradient of directness. In the case below, we are clearly towards the other end of the gradient, where D's silence speaks volumes:

Extract 2 (W:PC: I 1-3 notation greatly simplified)

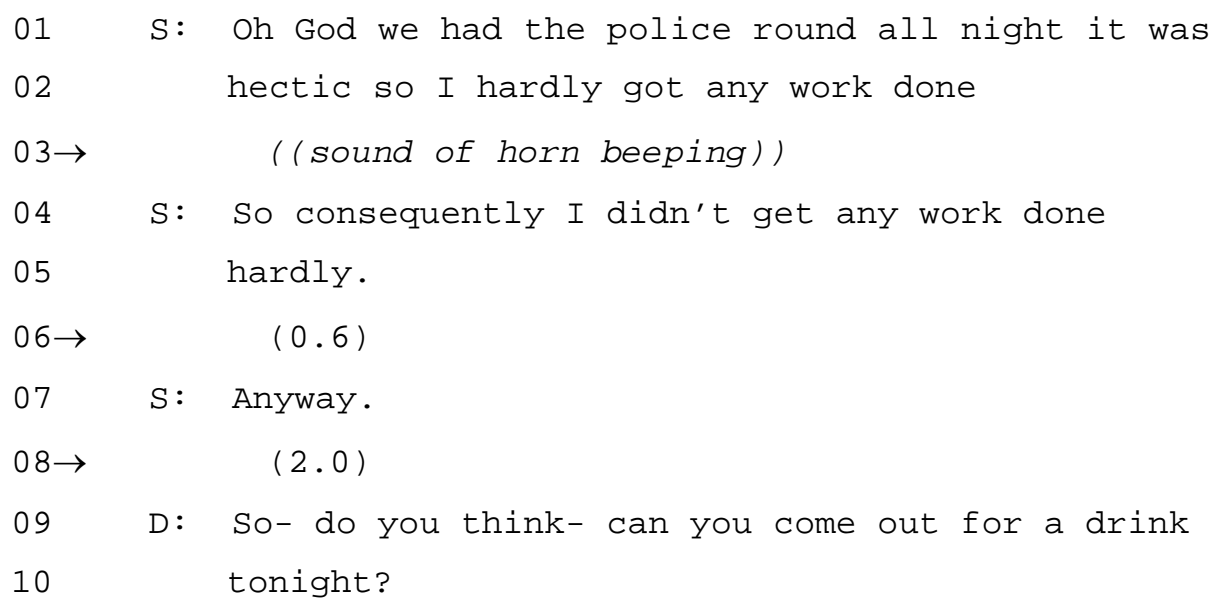

$\mathrm{S}$ is recounting a tale about not getting work done but, unlike speaker $\mathrm{L}$ in Extract 2 above, speaker D is not taking their opportunities at turn-transition points (arrowed) to express encouraging news-receipts. Indeed when D does 
take a turn (line 9), it is after a markedly long silence, and takes the form of a topic-changing invitation to come out for a drink. Invitations project agreement, or replies of some kind, so were S to try and re-establish the topic of their undone work, they would have to pay the cost of being as disaffiliative with D's new project as $\mathrm{D}$ was to theirs.

The gradient of discouragement from gentle to brusque is not one-dimensional. There will be many factors in play in deciding where to place your intervention, and, in institutional settings, some of these will turn on the view that the practitioner has of the client, and of the client's interests vis-à-vis those of the institution. In the body of the chapter we shall see how those concerns play out differently in psychotherapy and in support for people with intellectual impairments.

\section{Interactions in adult psychotherapy, and between residential support staff and adults with intellectual impairments}

The two kinds of interaction I shall report are quite different in terms of the clients' cognitive powers and their reasons for engaging with the practitioner. Nevertheless they share the feature of the practioner making space for the client 
to tell a trouble, and to then propose some assessment of it - or to manage the tale, if it strays outside what the practitioner considers to be its appropriate boundaries.

In talking about psychotherapy I shall concentrate on therapies which have a programmatic approach to their interactions with clients, where the transitions between troubles-telling and other phases of the interaction are more visible and more obviously policed. In Cognitive Behaviour Therapy, for example, therapists are meant to work to a clearly set-out schedule of activities within any one therapeutic session. Figure 1 is an example of a training manual's description of the phases that the therapist must go through. 
Session structure and outline: early phase of treatment

1. Greet patient

2. Perform a symptom check.

3. Set agenda.

4. Review homework from previous session.

5. Conduct cognitive-behavior therpy (CBT) work on issues from agenda

6. Socialise to cognitive model. Teach basic CBT concepts and methods.

7. Develop new homework assignment.

8. Review key points, give and elicit feedback, and close session.

Figure 1: An example of a programme for a therapeutic session (from Wright at al., 2006, p. 78)

Even if the experienced CBT therapist does not stick fixedly to this brief, and even in other kinds of psychotherapy where there are less structured phases to go through, there will necessarily be times when the client's long rehearsal of their troubles would be inconsistent with the kind of activity cast, in CBT terms, as 'set agenda' (which more loosely would be something like 'agree with the client what would be done in that session') or 'develop new homework assignment' (perhaps 'make recommendations as to what the client might usefully do before the next session'). And if the client's talk does run, on, then 
there is a dilemma. The therapist will have a specific therapeutic or managerial objective in mind which is to be pursued, even at the expense of seeming to be unresponsive to the client's troubles-telling.

How is the practitioner to respond? Text-books (for example, Dryden, 2007) are not unaware of such issues, but they lack detail in suggesting what the practitioner is to do. As Peräkylä and Vehviläinen (2003) observe about psychotherapy practice, textbooks may sometimes offer idealised examples but such idealisations can only get across what the author believes is the general 'feel' of an interaction, and may be wildly different from the specifics of actual talk. Conversation Analysis will help. As Peräkylä and Vehviläinen (2003) point out, a close analysis of recorded encounters will reveal significant and unsuspected detail in how therapists actually keep the client focussed.

With regard to the relationship between support-staff member and adult with an intellectual disability, the encounter is rarely so formally structured, yet there are many occasions in which staff an d client are engaged in some activity which provides for the staff member to ask the client to report on an event of concern or interest, either for purely informational reasons (the staff may need to know if there is anything wrong, or troubling the client) of out of an educational motive (the staff may need to test the client's understanding of such 
things as health practices). Her the exchange takes on the basic feature of interest to us: a space3 is provided for the client to report a concern, and that report may or may not 'fit' the boundaries allowed it by the practitioner.

Conversation Analysis (CA) is mostly applied to ordinary conversation, but has a developing interest in institutional encounters. Indeed, it has a long history of looking to see how therapy (and mental-health work in general) gets done in practice, beginning in the late 1960s with Harvey Sacks' account of an emergency psychiatric helpline and an adolescent group therapy session (both later published in his posthumous lectures; see Sacks, 1992). There has now accumulated quite a body of CA or CA-inspired work in therapy. The collection edited by Peräkylä, Antaki, Vehviläinen and Leudar (2008) shows therapists' practices in initiating actions and in responding to what the client offers to the session. Contributors to that collection identify a number of practices that the therapist uses in encouraging the client to talk, and to progress the session by offering formulations, reinterpretations, assessments and repairs of the client's words (and, by extension, the client's view of the events he or she was recounting).

In intellectual disability, Yearley and Brewer's (1989) pioneering work effectively established that people with all but the most severe intellectual 
disabilities were to be taken to have interactional, if not always linguistic, competence. Since then, CA-informed research has proceeded to fill out what we know about both voices in the dialogue: the practices of people with disabilities, and the practices of those around them - who often get, or take, a larger slice of the conversational cake. But the person with intellectual disabilities does not talk in a vacuum; Marlaire and Maynard's work (e.g. (Maynard and Marlaire 1992) redirected people's attention off the client and onto the practitioner. They studied how the tester and testee collaborated in educational assessment sessions, and identified how the practitioner could induce the testee to act less competently than they would do in ordinary conversation, or in conversation less driven by institutional objectives. Their work, and subsequent work by researchers studying interactions in more natural settings, (e.g. Williams, 2010; Antaki, Finlay and Walton, 2009) has made CA researchers more aware of the interplay between the practitioner's talk and that of the client, and allowed us to see their interdependence.

These two traditions of applied CA form a useful backdrop to the practices we have in our sights here: how a therapist, working with people with mental health issues, or a support staff member, working with adults with intellectual disabilities, may steer the client's talk in the direction that the institution requires. 


\section{Seven conversational practices to discourage the client's trajectory and keep the session institutionally "on track"}

A given turn at talk opens up a space for a class of next action (thus a summons requires a response, a question requires an answer, a news report requires a

news receipt, and so on - for a recent magisterial account of conversational sequences, see Schegloff 2007). When a client is making her or his report, that usually projects some sort of appreciation (a new receipt or an assessment). That keeps the interaction going on its trajectory, and the client is enabled to carry on. What we shall see, however, is that the practitioner can meet the client's words with a gradient of responses that, on the contrary, redirect, or try to redirect, the client's progress. The practitioner's redirections range from giving only minimal receipts of what the client has said, even when this would otherwise have warranted expansion, all the way to explicit active topic shift which takes a more directive role. Such deviation is marked, and makes the talk go off on an alternative trajectory from the one that the previous speaker had indicated.

To prefigure what we shall see, the gradient is composed of the following practices, in ascending order of explicit direction (building on five practices identified in Antaki and Jahoda, 2010): 
- minimal receipt of newsworthy announcements

- non-request for clarification of confused narrative.

- repeat of C's turn, or part of it

- formulation which closes the topic

- orientation to the need to keep on track

- non-engagement with client's talk

- explicit rejection of client's track

The practices are not exclusive, and we shall see how a practitioner may use a combination of practices, either across subsequent turns at talk or within one turn.

(1) The practitioner offers only a minimal receipt of announcements

When a person reports some event as an announcement, it can be met by a range of more or less encouraging receipts (Heritage, 1984). Therapy sessions, certainly, are environments where clients are encouraged to announce their concerns, and they require at least acknowledgement by therapist (active listening is a phrase often used, in therapy texts, to describe appreciating the client's situation). Equally, a person with intellectual disabilities may well be 
asked to report on events in their day to day lives as part of what is called person-centred care. Again, such reports can be met more or less encouragingly. In all cases, the practitioner may judge that after a certain moment, the time is not right to encourage the client to elaborate on a given report. In the case of the CBT therapist for example, it would be unwelcome for the client to elaborate on their troubles in the in an agenda-setting phase, or in a homework review phase. In extract 1 below, the therapist is making a list of things to cover in the session, and asks the client for clarification of how to word an item on hearing voices. In this, as in all the extracts used, any names that appear are pseudonyms, and any other identifying material has been removed or altered. "C" is the client, and " $\mathrm{T}$ " the therapist.

\section{Extract 3 CBTM: SH/JR Session 1, $\min 16^{\mathrm{ii}}$}

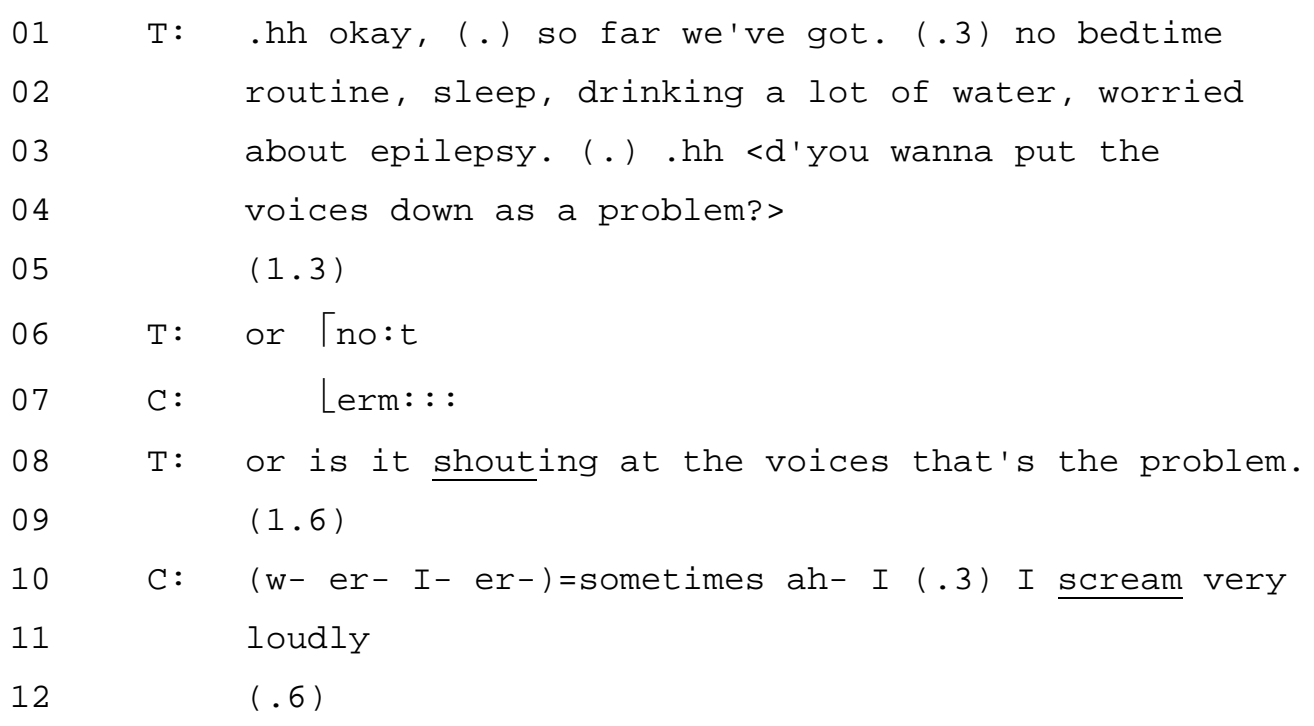




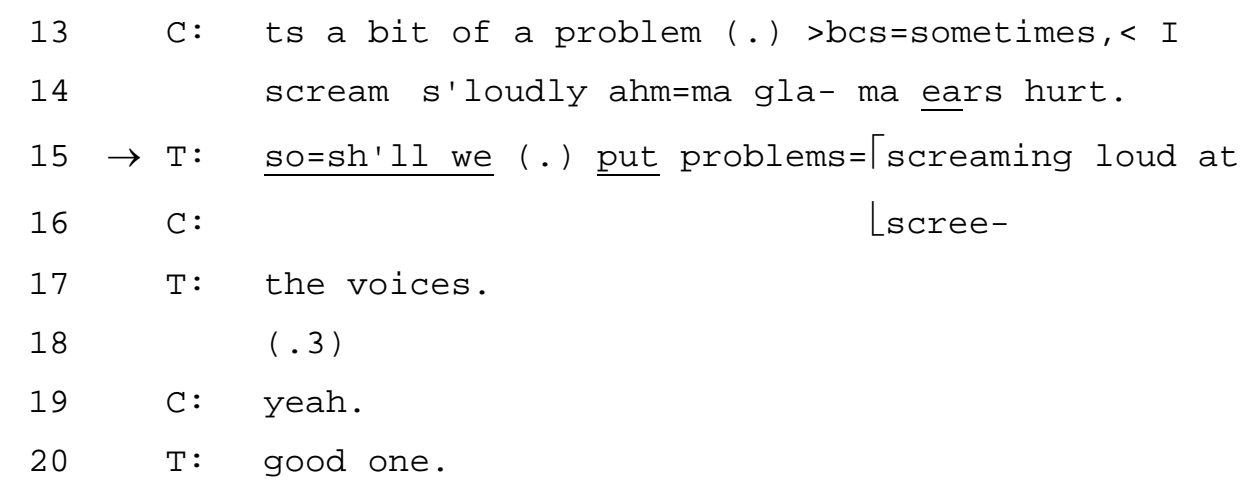

In the extract above, the client's announcement sometimes I scream very loudly receives no acknowledgement from the therapist. The client then upgrades the report to sometimes I scream so loudly my ears hurt. Such 'news announcements' (Heritage, 1984) strongly project explicit new-receipt by the listener (for example: really? do they? oh? among the more encouraging ones; see Heritage 1984). But the therapist gives no assessment or receipt whatever, instead meeting the announcement with a proposal of how to record the client's experience (the arrowed line 15), in line with the current business of the session, which is setting the day's agenda.

(2) The practitioner does not request clarification, even for unclear narrative

In both sets of interactions, clients' accounts may be difficult to follow, for various reasons; in some cases it is due to cognitive difficulties in formulating language, and in other cases it might be because the client is overwhelmed by 
their feelings, and in still other cases it may simply be due to the complexity of the events they are reporting. In everyday talk, the listener has a range of practices open to them to prompt the speaker to clarify what he or she is saying. Such prompts encourage the speaker to go on, and to elaborate. What is noticeable in the data here is that the practitioners will, even when there is a manifest obscurity in what their client is saying, forgo such prompts for clarification. The upshot is that the client's tale runs into the sand. Consider what happens below, in Extract 4. The therapist asks the client to explain how he felt (lines 1-2) about an episode which had been established a little before this extract begins. As you will see, the client starts off with an answer to that question, but quickly veers off into a narrative report about the events of a certain day.

In the extract, blank space between brackets identifies talk which is impossible to transcribe, and words in brackets represent a guess at what the client possibly said.

Extract 4 AJ4 min 15.00 "Buzzer"

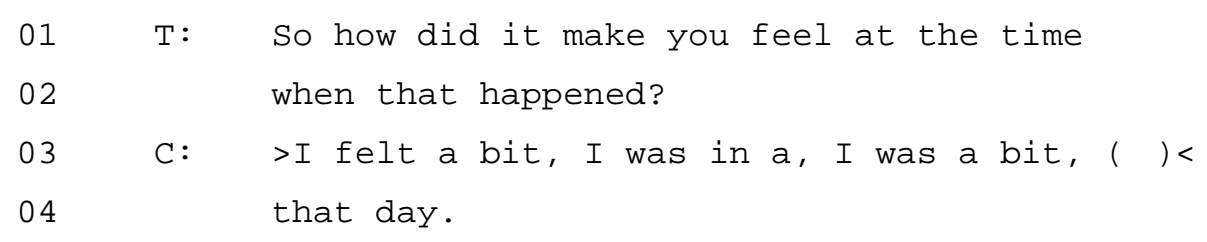




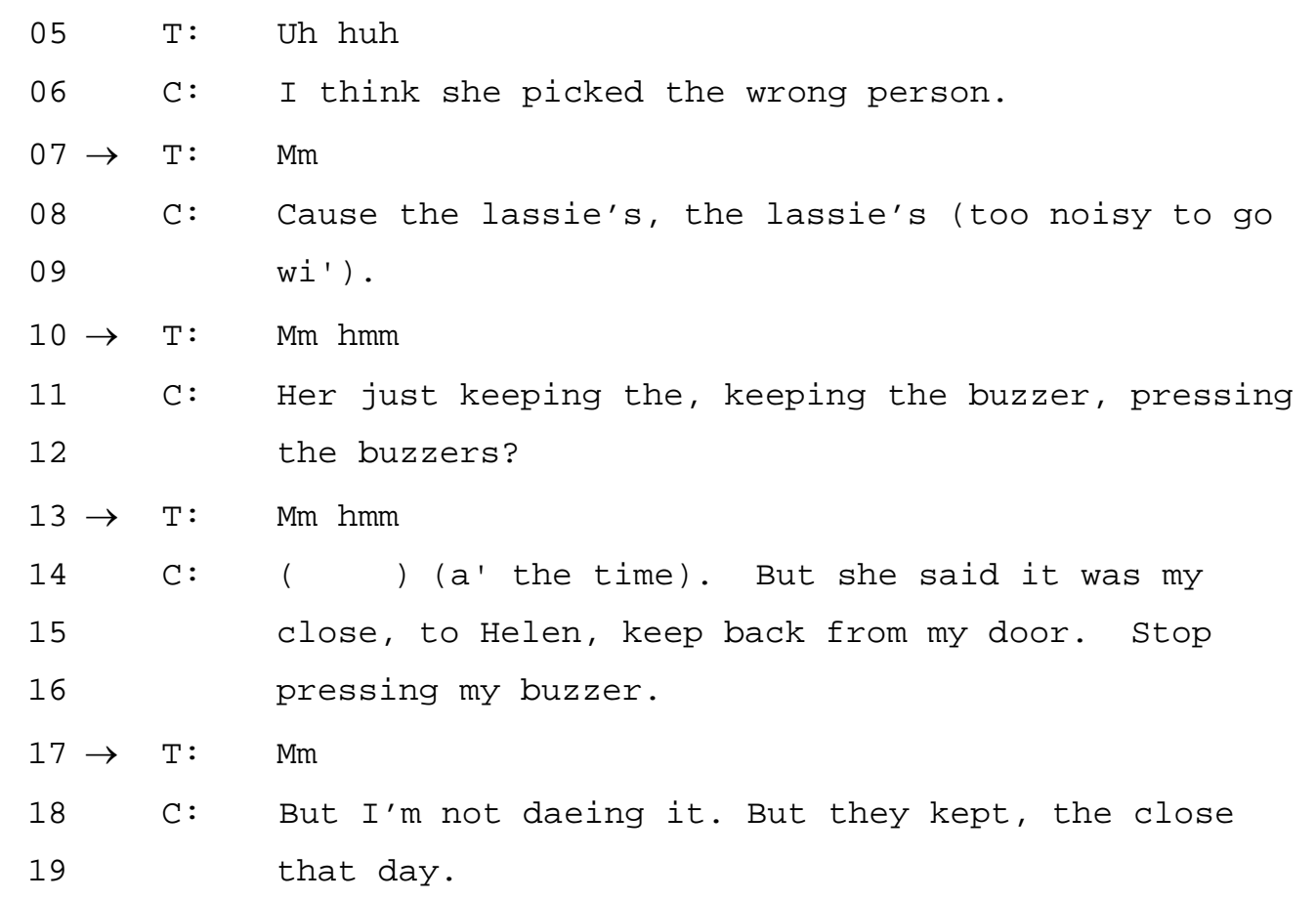

Possibly the client means his report on the events at his home to shed light on his feelings, but what he is saying is very unclear (possibly it involves troublesome neighbours). The doubt that it might not to be about 'feelings' at all seems to induce the therapist to forego any directive prompt that would encourage elaboration. At the arrowed lines, the therapist receives this narrative with the most minimal "continuers" (Schegloff, 1982) which signal only that he is attentive, but forgo clarification of the story, on the basis (we presume) that the story is a distraction from the therapeutic goal of the moment, namely to get the client to articulate his emotional reaction rather than the details of the physical events. 
(3) The practitioner echoes part of client's turn as a prelude to topic shift

Topics in conversation are often shifted 'step-wise' (Jefferson 1984) - that is, not by an abrupt change of gear (though that can happen) but by some prefatory work that projects the closure of one topic and the potential to open another. One way of doing the prefatory work that seems apt for the institutions of therapy and supporting people with intellectual impairments is to repeat back to the speaker something they have said, as a form of confirmation or understanding check. This generates the expectation that the client will confirm their 'own words', and allow the practioner a more open field in which to project her or his own turn. In the extract below, from a psychotherapy session, the therapist is in the process of getting the client to list episodes of distress. However, the client takes the opportunity to go beyond mere listing, and begins a narrative, seemingly involving an episode of domestic troubles. Note how the practitioner summarises what the client says as a preface to moving on by 'just thinking about' a related topic. 


\section{Extract 5 AJ4 min 9.00 "moonlighting"}

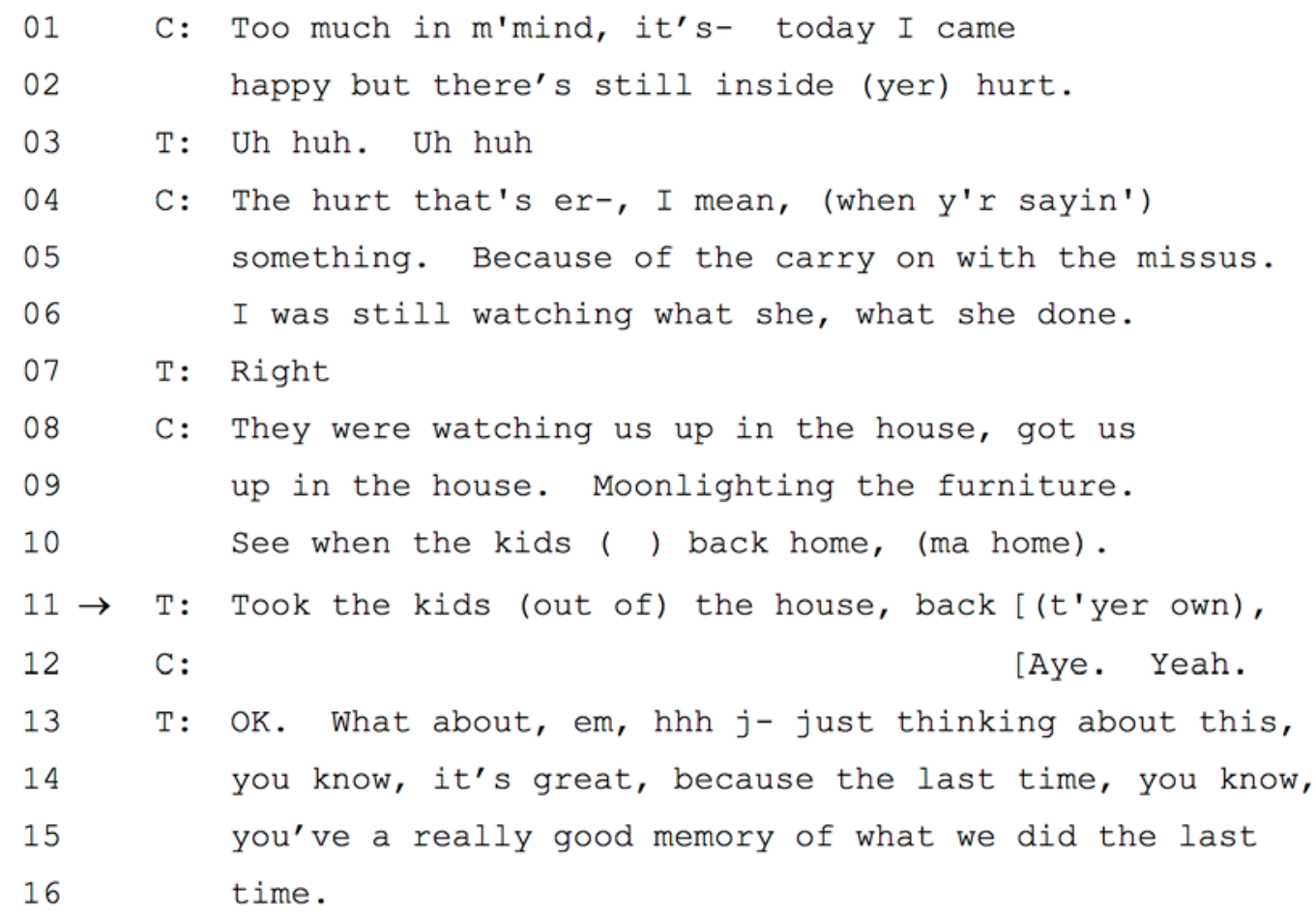

The client is relating a story, which may be over-elaborate for the needs of this stage of the session. The therapist's summary echo and confirmation at line 11 moves the talk away from the vivid detail of the story, and the demands of contiguity (Sacks, 1987), and prefaces a move the conversation back onto the business of the session. 
(4) The practitioner offers a 'formulation' of client's talk which closes the topic

In the preceding section, we saw how a therapist could 'echo' and clarify the client's actual words. That is a specific variant of a more general practice of proposing to a speaker what is ostensibly a mere summary or natural consequence of what they've just said - what Heritage and Watson call 'gist' and 'upshot' formulations. What gives a formulation extra spin, however, which can be used to bring the talk back 'on-track', is that it deletes a certain part of what the client said, and, in selecting another part, transforms it to some degree (Heritage and Watson 1979).

In this example, the therapist is taking down the client's history in an early session. The objective is to make a record of his episodes of voice-hearing, and specifically their extent (not their content).

Extract 6. CBTM AG/HD session 1 "Nasty voice"

1 c b't it j'st seem to be a nasty voi-I might feel a bit

2 (.)bit better, when soon's=I (.6) er $y^{\prime} t-(1.0)$

3 >wunnit, wunnit< wite (.) wite- why'it says summi'

4 like er (.3) (.) er (bitch) or (tick=or) summin' like

5 'at $>$ n'ye-< (.4) .h (.) but ee- ee- it does (.) (or

6 dog or whatever) (.) it's very er-it's 


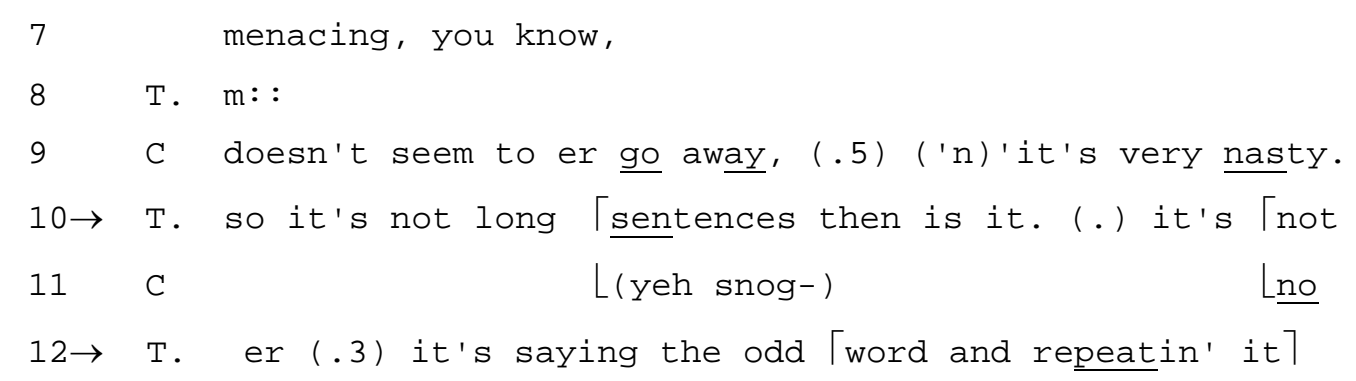

The client is understandably concerned to get across the subjective emotional tone of the voices he hears, but the therapist has a different objective: to determine the (as it were) objective extent or depth of the hallucination- how long it lasts, how articulate it is, and so on. Hence, rather than orient to the troubling nature of the voice, (it is nasty and very menacing), the therapist at line 10 formulates the issue as being (merely) one of sentence length: it's not long sentences then, it's not er it's saying the odd word and repeating it. This deletes the nastiness of the voice in favour of the diagnostic issue of articulacy. The client at first plays along (yeh repeatin whole sentences) but then he adds more detail (not shown), again of a troubling sort: hittin someone or whatever or losing me rag (an idiom for 'losing my temper', in British English). Again the therapist formulates the trouble away: yeah so you've been doing a lot of writing down. This allows her to bring the talk back to the current agenda. In the example below, from a different pair of client and therapist, the therapist has the same recourse to a minimising, topic-closing formulation, again formulating a neutral gloss on a highly-charged report: 


\section{Extract 7. CBTM SH/JR 07/07/98 min 47 "Rubbing"}

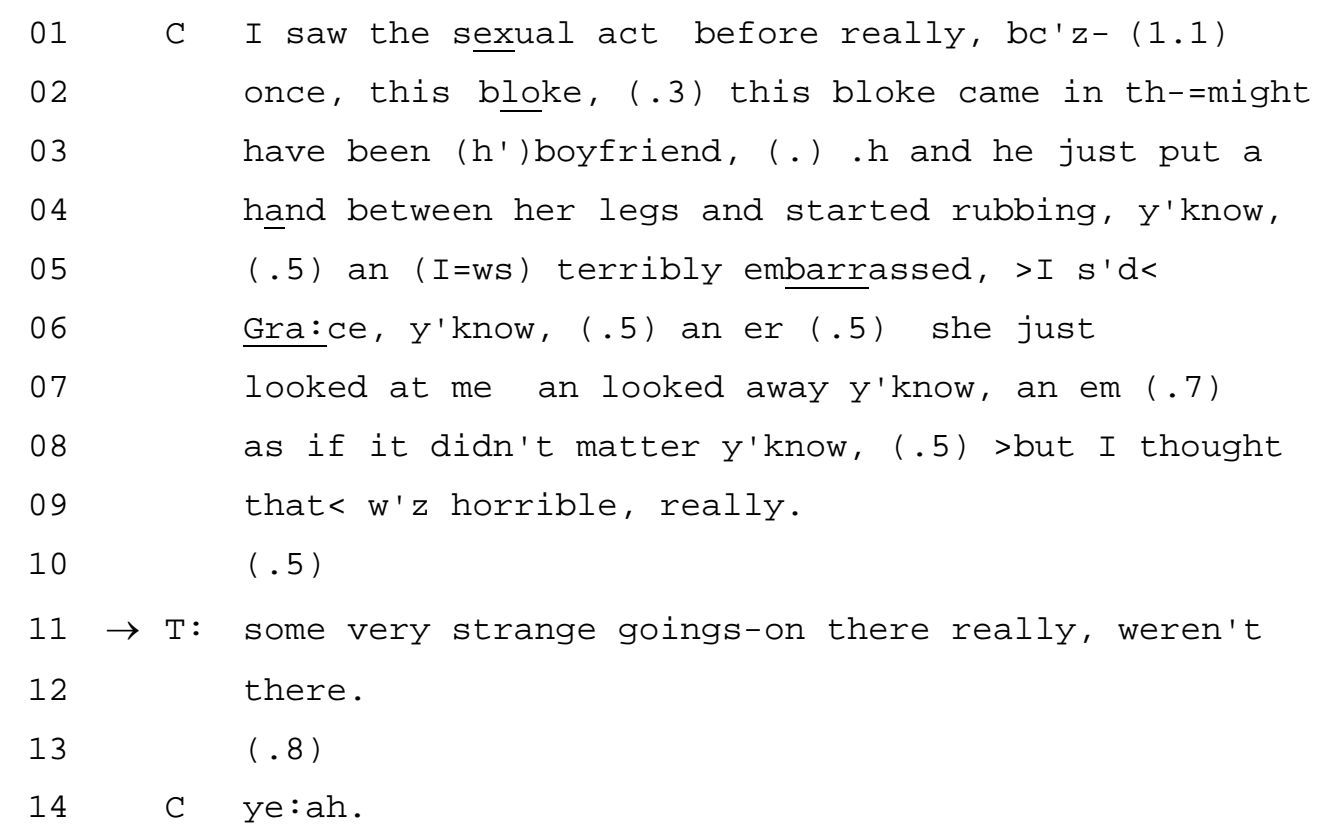

At the point in the session where this exchange takes place, the therapist is trying to get the client to agree to do 'homework' - to practice certain behavioural and cognitive procedures which will combat negative memories. The client nevertheless dwells on a narration of the details of a distressing childhood experience; such troubled announcements provide normally for encouraging news receipts. As we saw in the example of the voice-hearer above, the therapist not only withholds such encouragements but goes further, and offers a neutral formulation of the client's trouble: some very strange goings-on there really, weren't there (lines 11-12). The formulation not only deletes the vivid detail of the tale, but - especially with the agreement- 
projecting tag question, solicits affirmation from the client. Thus an ostensibly simple summary of 'her own words' has been used to bring the topic to a less distressing and more neutral close and allow the therapist to proceed with the task of setting the homework.

(5) The Practitioner explicitly orients to the business at hand

We are going up the gradient of what the practitioner can do to pull the client's talk back on track. As we move towards more directive tactics, we see that the practitioner can explicitly orient to either the management of the interview, which we shall see later, or, in the first case we see below, to reintroduce a question that has still not been dealt with satisfactorily.

In extract 8 immediately below a psychotherapist is in the process of getting the client to say how he felt at certain points during the previous week. The client has nominated an occasion on which he felt angry with his ex-wife, but at line 7 he switches time-frame to the present, and report his current feelings. Note how the therapist receives this off-track talk.

Extract 8. AJ4 min 11.30: "Hurts"

$01 \mathrm{C}$ : And then she phones back, comes later and says, 


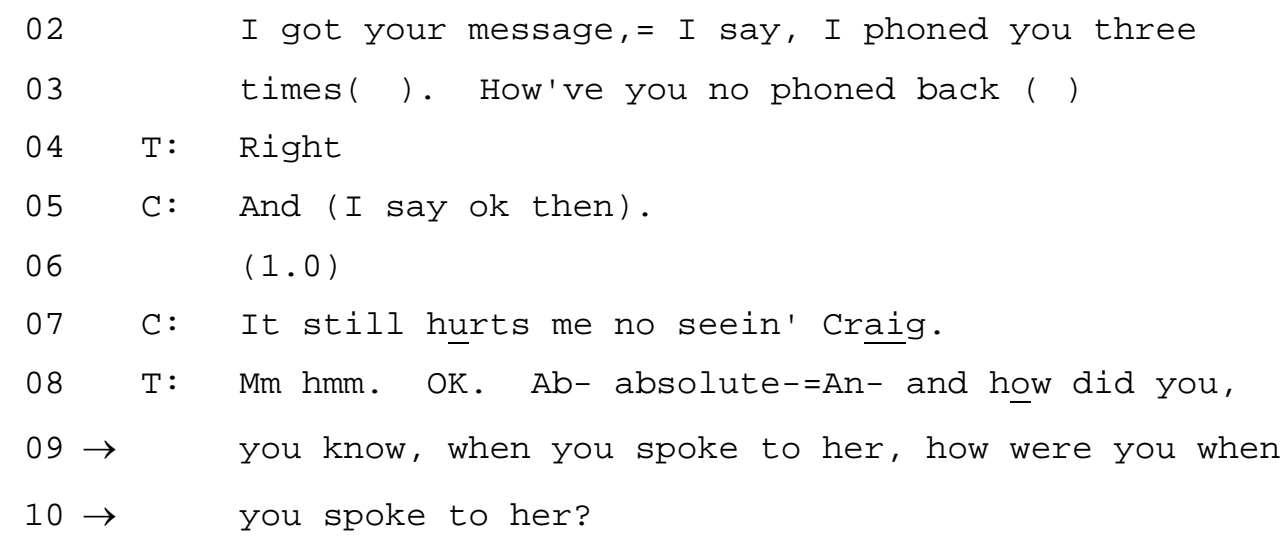

After the client's disclosure of his current feelings, it would have been open to the therapist to enquire further into the client's distress at not seeing his son. Instead, what we see is the therapist respond with a minimal receipt (as in examples seen earlier) and explicitly reissue the question that is pending - how the client actually felt during that episode: how were you when you spoke to her?

A further, and still more directive practice is open to a practitioner - an orientation to the management of the talk. By its very nature, the structure of an interaction between client and practitioner is one where there is a more-or-less fixed set of objectives to be got through; and because of the asymmetry in who has rights to move the talk along, it falls to the practitioner to monitor this progress. They can invoke it explicitly, as in this case, which occurs in the early part of the session where a therapist is generating an agenda for the meeting. 
We join after the client has been talking for some time about her difficulties in getting to sleep:

Extract 9. CBTM: SH and JR Session 1 min 6: "Sleeping"

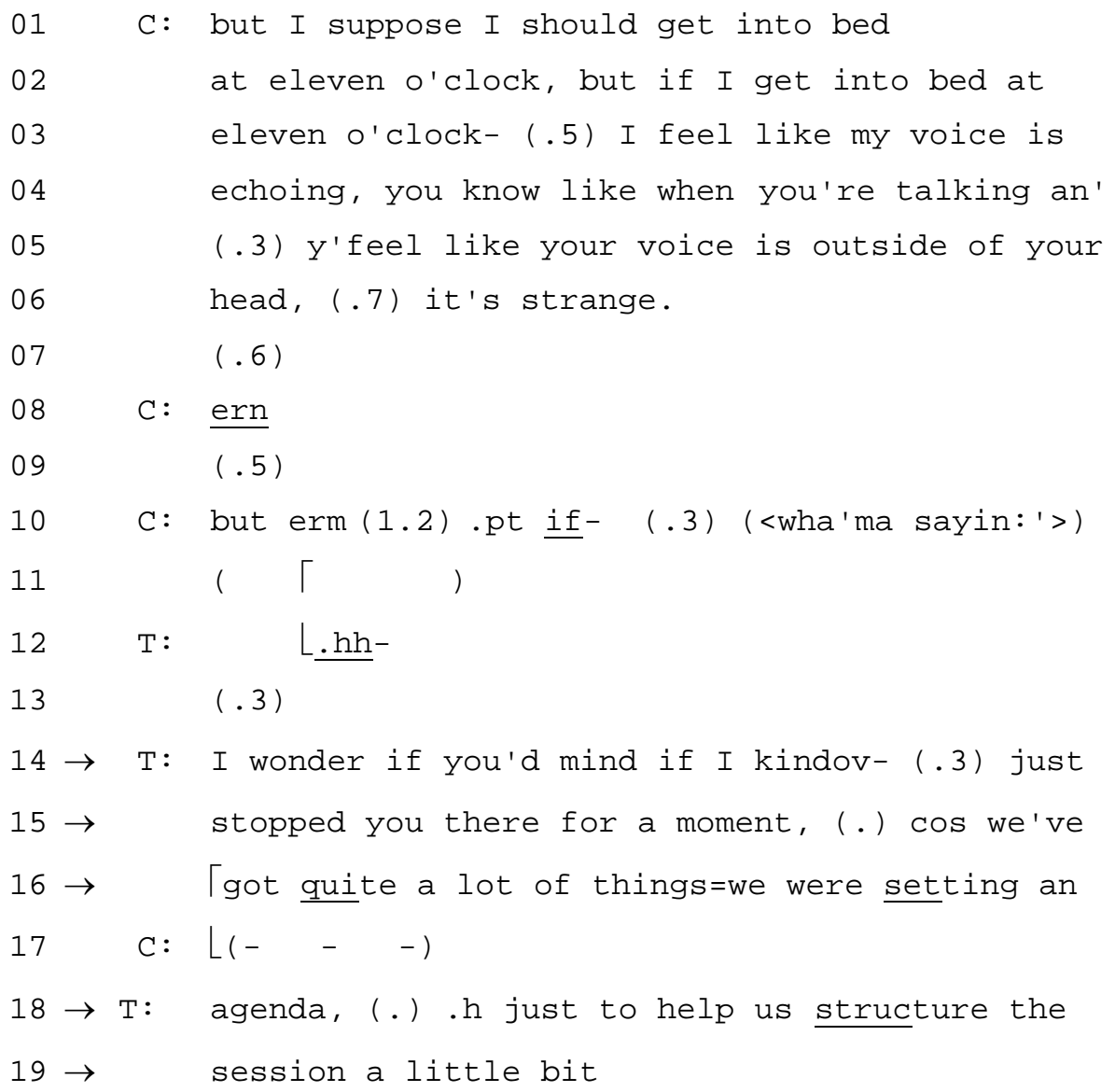

The client has been talking for some time about her difficulties in getting to sleep and at line 10 issues what might be construed as an invitation to the therapist to help her formulate her words and describe her feelings more accurately. But this would be to prolong a troubles-telling in a part of the 
session devoted to agenda-setting, and the therapist takes the opportunity instead to issue a politely marked request that the client stop there. We are clearly moving up the gradient of direction.

(6) Non-engagement with the client's talk

In the data from interaction s between support staff and adults with intellectual disabilities, but not in the therapy sessions, it was quite common for the practitioner to 'tune out' clients' talk that was considered to be irrelevant or distracting. Even if the client explicitly solicited a response from the staff member (in the form of a question, for example), the staff, on many occasions, did not abide by the expectation to provide the response, and instead pursued a different trajectory (either involving that client, or involving others, or on some other business). Here is a typical example. Staff members Kath and Oonagh are establishing where each of the residents wants to go on holiday. While Oonagh is recording another resident's choice, Alec addresses talk to her, but she does not respond (line 3). 


\section{Extract 10: CHW VD17 4:19. Holidays / who's that?}

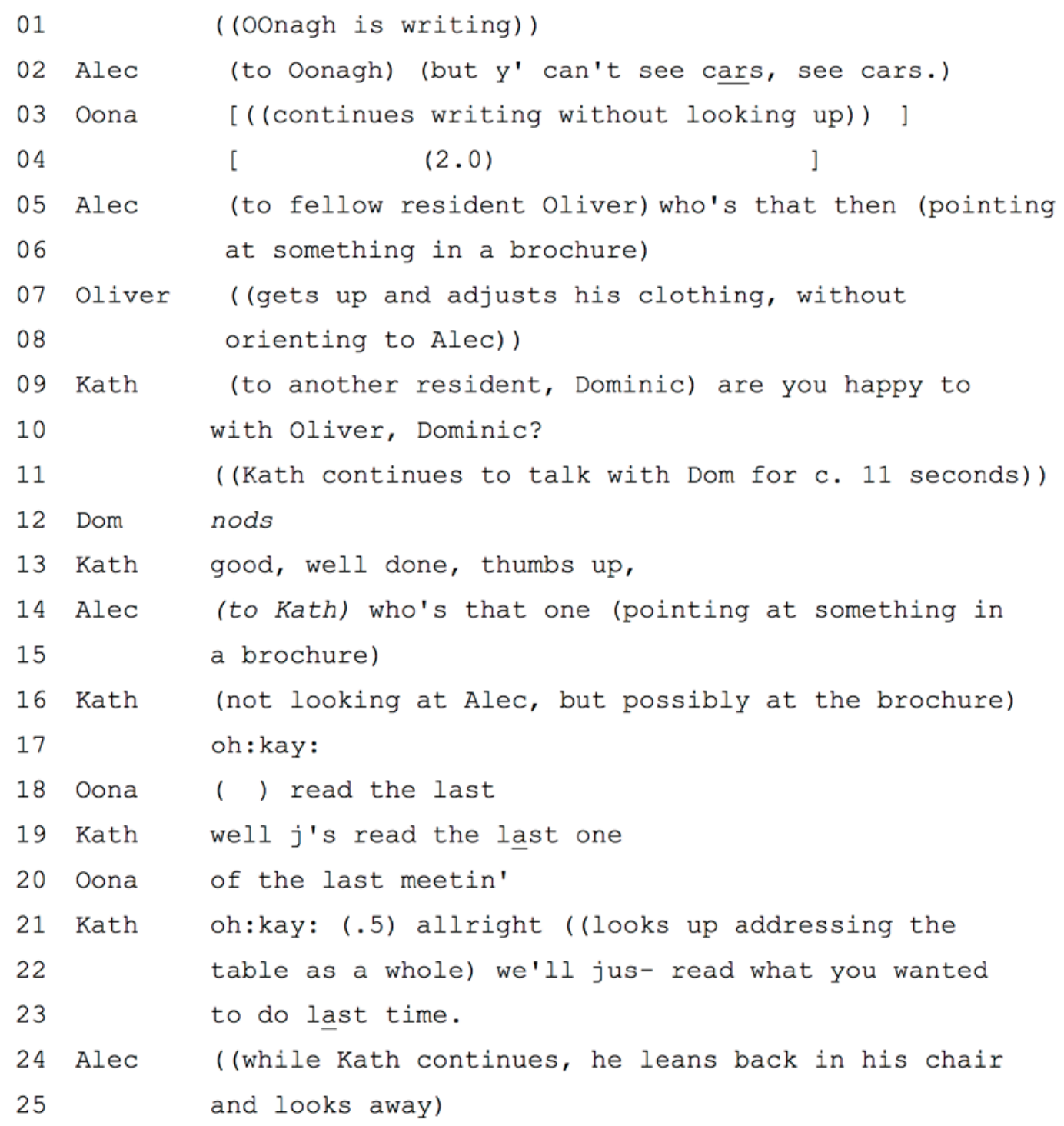

After failure to get a staff member to respond to his observation (which is not well formatted), Alec poses a question to a fellow resident, but again is unsuccessful. Then he waits until Kath has finished her questioning of Dominic (signalled by her assessing his responses as 'good well done, thumbs up, line 
13), and asks her a direct question (line 14-15). Kath's utterance at this point (lines 16-17) is ambiguous as to its orientation. It may be an acknowledgement of Alec's question (though it is not a reply to it), but it may be a preface for a general announcement of next topic. After a prompt from Oonagh, Kat's full turn at lines 21-23 reveals it, at least retrospectively, to have been this general announcement. So in this brief episode, Alec's efforts to get the talk onto his own track have been ignored by the staff, who pursue the institutional objective in hand.

(7) Explicit rejection of the client's track

The most outright discouragement of the client's talk is to explicitly reject it as a topic for joint attention. This does not happen in any of the therapy data I have seen, but, though rare, does happen in interactions between support staff and adults with intellectual impairment nt. Here is an example, from an occasion in which staff and residents are having lunch. Dominic (who has some language, but tends to use gestures and idiosyncratic signs) is responding to a joke by Alec, another resident, who wants to "put him in a skip" for bringing too many pepper pots to the table. Staff member Peter is trying to understand what Dominic is gesturing and saying. 


\section{Extract 11. BW-VD11 09.40 "Dunno"}

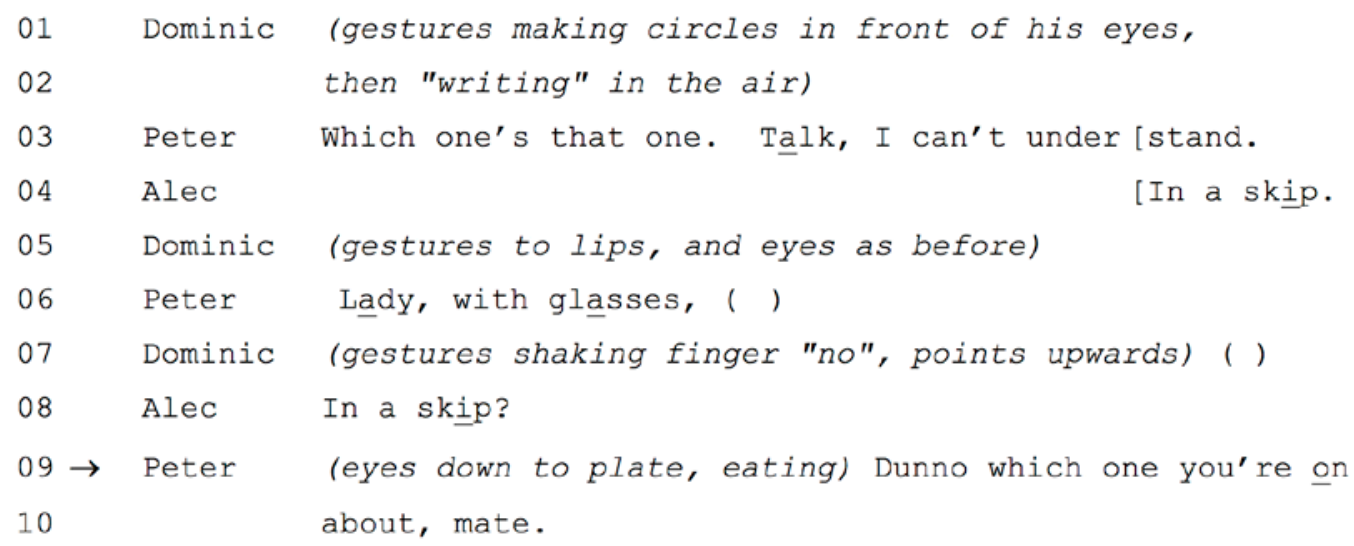

The resident's attempt to tell his tale, in his own way, is discouraged by the staff member: at first in an exhortation to speak (line 3), even though this resident is not a confident language user; and finally an explicit refusal to engage with his narrative project (lines 9-10). As I say, I have no examples of this in the therapy data, which suggests that such disengagement is not appropriate to the therapeutic relationship; but it does happen in care settings, where the institutional imperatives are very different.

\section{Concluding Comments}

The focus of the chapter has been on the interaction type of the problem-based interview, and the professional format of counselling or support-based 
interaction between clients with cognitive difficulties and their practitioners. The specific question we asked was how the practitioners dealt with the particular communicative task of the troubles narrative - especially, the narrative that went "off-track". We have seen how practitioners have a spectrum of practices to deal with their clients' talking such cases; that is to say, when it delays what the practitioner considers to be other, over-riding objectives for the conversation to fulfil at that point. We saw examples from cognitive behaviour therapists, and from support staff working with adults with intellectual disabilities. Least discouragingly, the practitioner could merely forgo offering receipt of newsworthy announcements, and at the most discouraging, they could issue an explicit rejection of the client's narrative. In between, in ascending order of directness, they could: let pass confused narrative; use a repeat of part of the client's turn as a pivot towards a different direction; formulate the client's talk in a way that closes the client's topic; and making an overt orientation to the need to keep the conversation 'on track'.

Sampling the interactions of two very different kinds of mental-health practitioner allowed us to see more of a spectrum than had we concentrated only on one - it was certainly the case that, although usage overlapped, the more directive end of the spectrum was only used by staff members in the care institution, and not by psychotherapists. Indeed, the kind of psychotherapy we 
sampled here (cognitive behaviour therapy) itself may also mandate the use of certain kinds of practice, and were we to investigate other kinds (psychodynamic psychoanalysis, for example, or Rogerian therapy), still other kinds of practices might come to light. The particular stations on the spectrum that we identify here, then, are only a provisional list. But it seems reasonable to say that these practices do form a collection, an that they provide the practitioner with a way of dealing with a recurrent institutional problem, to be solved by means consistent with their institutional imperatives.

\section{References}

Antaki, C., and A. Jahoda. 2010. "Psychotherapists' Practices in Keeping a Session "On-track" in the Face of Clients' "Off-track" Talk." Communication \& Medicine 7: 11-21.

Antaki, C., WML. Finlay, and C. Walton. 2009. "Choice for People with an Intellectual Impairment in Official Discourse and in Practice.” Journal of Policy and Practice in Intellectual Disabilities 6(4): 260-266.

Dryden, W. (ed). 2007. Dryden's Handbook of Individual Therapy. London: Sage.

Heritage, J.. 1984. “A Change of State Token and Aspects of Its Sequential Organisation.” In Structures of Social Action, ed. by J. M. Atkinson and J. Heritage, 299-345. Cambridge: CUP and Paris: Editions de la Maison des Sciences de l'Homme. 
Heritage, J.. 1985. “Analyzing News Interviews: Aspects of the Production of Talk for an Overhearing Audience.” In Handbook of Discourse Analysis, Vol. 3, ed. by T.A. Van Dijk, 95-117. London: Academic Press.

Heritage, J.C., and D.R. Watson. 1979. "Formulations as Conversational Objects." In Everyday language: studies in ethnomethodology, ed. by George Psathas, 123-62. New York: Irvington

Hutchby, I.. 2005. “'Active Listening': Formulations and the Elicitation of Feeling-talk in Child Counselling." Research on Language and Social Interaction, 38 (3), 303-329.

Jefferson, G.. 1984. “On Stepwise Transition from Talk about a Trouble to Inappropriately Next-positioned Matters.” In Structures of Social Action: Studies of Conversation Analysis, ed. by J.M. Atkinson and J.C. Heritage, 191-222. Cambridge, UK: Cambridge University Press.

Jefferson, G.. 1988. "Preliminary Notes on a Possible Metric which Provides for a 'Standard Maximum' Silence of Approximately One Second in Conversation.” In Conversation, ed. by D. Roger and P. Bull, 166-196. Clevedon, England: Multilingual Matters.

Peräkylä, A., C. Antaki, S. Vehviläinen, and I. Leudar (eds.). 2008.

Conversation Analysis and Psychotherapy. Cambridge: Cambridge University Press.

Peräkylä, A., and S. Vehviläinen. 2003. "Conversation Analysis and the Professional Stocks of Interactional Knowledge.” Discourse \& Society 14 (6): 727-750.

Raymond, G.. 2003. "Grammar and Social Organization: Yes/No Interrogatives and the Structure of Responding.” American Sociological Review 68: 939-967. 
Sacks, H.. 1987. “On the Preferences for Contiguity and Agreement in Sequences in Conversation.” In Talk and Social Organisation, ed. by G. Button and J. R. Lee, 54-69. Clevedon: Multilingual Matters.

Sacks, H.. 1992. Lectures on Conversation. Oxford: Basil Blackwell.

Schegloff, E. A.. 1979. “The Relevance of Repair to Syntax-for-Conversation.” In Syntax and Semantics, Volume 12: Discourse and Syntax, ed. by T. Givon, 261-286. New York: Academic Press.

Schegloff, E. A.. 1982. “Discourse as an Interactional Achievement: Some Use of 'uh huh' and Other Things that Come Between Sentences.” In Analyzing Discourse: Text and Talk (Georgetown University Round Table on Language and Linguistics, ed. by D. Tannen, 71-93. Washington, DC: Georgetown University Press.

Schegloff, E. A.. 2007. Sequence Organisation in Interaction. Cambridge: Cambridge University Press.

Shakespeare, P.. 1997. Aspects of Confused Speech: A Study of Verbal Interaction Between Confused and Normal Speakers. Mahwah, NJ: Lawrence Erlbaum Assoc Inc.

Williams, V.. 2010. Disability and Discourse: Analysing Inclusive Conversation with People with Intellectual Disabilities. Chichester, Wiley-Blackwell.

Wright, J. H., M. Ramirez Basco, and M. E. Thase 2006. Learning Cognitivebehavior Therapy: an Illustrated Guide. Arlington: American Psychiatric Publishing. 


\section{Transcription Symbols (adapted from the Jefferson system standard in Conversation Analysis)}

\begin{tabular}{|c|c|}
\hline$(\cdot)$ & Just noticeable pause \\
\hline$(.3),(2.6)$ & Examples of timed pauses, in seconds \\
\hline $\begin{array}{r}\text { word }[\text { word }] \\
{[\text { word }]}\end{array}$ & $\begin{array}{l}\text { Square brackets aligned across adjacent lines denote } \\
\text { the start and end of overlapping talk. }\end{array}$ \\
\hline$. \mathrm{hh}, \mathrm{hh}$ & $\begin{array}{l}\text { In-breath (note the preceding full stop) and out- } \\
\text { breath respectively. }\end{array}$ \\
\hline wor - & A dash shows a sharp cut-off \\
\hline wo:rd & $\begin{array}{l}\text { Colons show that the speaker has stretched the } \\
\text { preceding sound. }\end{array}$ \\
\hline (words) & A guess at what might have been said \\
\hline$(\quad)$ & Talk too unclear to merit even a guess. \\
\hline word, WORD & Underlined sounds are louder, capitals louder still \\
\hline${ }^{\circ}$ word ${ }^{\circ}$ & Material between "degree signs" is quiet \\
\hline $\begin{array}{l}>\text { word word }<<\text { word } \\
\text { word }>\end{array}$ & Inwards arrows show faster speech, outward slower \\
\hline wo $(h) r d$ & $\begin{array}{l}\text { (h) shows that the word has "laughter" bubbling } \\
\text { within it }\end{array}$ \\
\hline ((gruff voice) & $\begin{array}{l}\text { Attempt at representing something hard, or } \\
\text { impossible, to write phonetically }\end{array}$ \\
\hline$\rightarrow$ & Analyst's signal of a significant line \\
\hline
\end{tabular}

\footnotetext{
${ }^{\mathrm{i}}$ Part of the material in this chapter is based on data and analysis in Antaki and Jahoda (2010)

ii I am grateful to Ivan Leudar for access to data marked "CBTM"
} 